\title{
JUVENTUDES EM MOVIMENTOS: Materialidades escolares, performatividades e inventividades
}

\author{
Juliana de Favere ${ }^{(*)}$ \\ Geovana Mendonça Lunardi Mendes
}

\section{OS MOVIMENTOS DE UM CAMINHO}

Este artigo é o recorte de uma pesquisa de doutorado em andamento que intenta produzir uma escrita que percorre, cartografa e segue os fluxos juvenis contemporâneos. A ideia é a criação de uma pesquisa-escrita-problematização em que sua produção são tentativas, que se desmancham ao tentar identificações ou resultados precisos. Porém, neste caminho, há estudos, conversas, rigor e invenções.

Com os autores escolhidos é possível problematizar o tema de pesquisa - juventudes - em suas micropolíticas e construir uma escrita movida por perguntas sem respostas e que desafiam a “[...] mapear para inventar espaços; melhor, para abrir no espaço outros espaços. Escrever e fazer mapas para produzir sempre novos começos... Novos modos de dizer.” (PREVE, 2010, p. 03).

Neste caminho, o objetivo deste recorte da pesquisa é cartografar os movimentos das juventudes contemporâneas num espaço de escolarização. Os movimentos cartografados percorreram por materialidades escolares, performatividades e inventividades, não de modo separados, mas embaralhados e na constituição de macro e micropolíticas. Os movimentos das juventudes são aqui entendidos como as vivências e as relações que lhes acontecem, possibilitam a produção de modos de subjetividades atravessada de relações de poder que atuam positiva e negativamente em micropolíticas de forças sujeitadas - dominação, docilidade e controle - e inventivas - criativas, potentes e singulares.

O campo de pesquisa que se acompanha as juventudes é uma escola estadual de ensino médio do interior do estado de Santa Catarina, localizado na região do Vale do Itajaí. Os movimentos foram registrados com um diário de bordo, com descrições e relatos das situações

\footnotetext{
${ }^{(*)}$ Juliana de Favere Doutoranda em Educação, Bolsista CAPES - Universidade do Estado de Santa Catarina (UDESC) E-mail: julifavere@gmail.com.

Geovana Mendonça Lunardi Mendes. Doutora em Educação (PUC-SP). Professora Pesquisadora do PPPGE/UDESC. Membro do OPE. Coordenadora de diferentes projetos nacionais e internacionais. Vice-presidente Sul da Anped. Email: geolunardi@gmail.com.
} 
corriqueiras, habituais e inusitadas. Houver também registros fotográficos, porém não foram explorados neste artigo.

Os escritos, as ideias e os relatos seguem o phylum maquínico dos movimentos das juventudes, sem capturar e criar uma 'mancha/marca'/identidade, mas se guia pelas juventudes, perseguindo-as sem alcançar e encontrar um fim. Como na relação do artesão e da madeira; ou do metalúrgico e do metal.

Diferente do molde, Deleuze e Guattari dialogam sobre o phylum maquínico como materialidade, natural ou artificial e que ao mesmo tempo é portador de singularidade e traços de expressão; “[...] essa matéria-fluxo só pode ser seguida [como] um artesão que aplaina segue a madeira, e as fibras da madeira, sem mudar de lugar." (DELEUZE; GUATTARI, 2007, p. 92). Não se altera, segue-se. O phylum maquínico é matéria, mas também movimento, numa variação contínua, que não é capturada, pois o movimento não cessa. Ele se produz enquanto se cria. Nesta coexistência, há micropolítica e seus acontecimentos, seus atravessamentos e suas singularidades em um mesmo procedimento/situação. Os atravessamentos pelas micropolíticas podem ser capturados, o que geram estrias, identidades e modos de subjetividade, como a escolarizada.

As ideias de Foucault (2005), Deleuze (2008), Deleuze e Guattari (2007) e Dussel (2014) provocam e impulsionam a discussão.

Com a produção dos dados pelo caminho da cartografia, percebeu-se que muitos movimentos dos jovens são possíveis tanto na ordem das normas e dos modelos, como brechas às micropolíticas como potências criadoras em que algo pode acontecer. Permeados pelas relações de poder, os dados indicam que os jovens afetam e são afetados pelos emaranhados de materialidades escolares, performatividades e inventividades.

\section{JUVENTUDES E ESCOLARIZAÇÃO: MICROPOLÍTICAS QUE FORMAM, PRODUZEM E FAZEM ALGO ACONTECER}

O cenário: escola, muros, pátio, corredores, salas, carteiras. Os personagens: professores, equipe pedagógica, pais, JOVENS. O enredo: currículo, disciplinas, aulas, encontros. As ferramentas: quadro-branco, materiais didáticos, projetores. A cena-escolar: organizada, alinhada, esquadrinhada. A disposição escolar está armada. O filme pode rodar: constituição de subjetividades escolares, que transcendem o espaço escolar; subjetividades para/na a vida. 
Diante do cenário 'armado' e 'pronto para rodar', algo interfere-soma-multiplica-incomodaprovoca o processo de escolarização. Materialidades escolares, performatividades, encontros, desencontros, conversas, disputas, amizades, inventividades.

As instituições escolares discutem, ensaiam, negam e são provocadas com as modificações rápidas e instantâneas de um planeta que se diz globalizado. O perfil das pessoas na contemporaneidade apresenta outras características de tempos anteriores; a informação e a comunicação parecem alargadas; os relacionamentos fluídos, as juventudes exacerbadamente (des)preocupadas com futuro ${ }^{1}$. As juventudes: muito jovens para decidir sobre suas vidas (futuras); precisam ser distanciadas das delinquências e do estado 'marginal' juvenil; “Art. 18. É dever de todos velar pela dignidade da criança e do adolescente, pondo-os a salvo de qualquer tratamento desumano, violento, aterrorizante, vexatório ou constrangedor"2; devem permanecer na escola; “Art. 53. A criança e o adolescente têm direito à educação, visando ao pleno desenvolvimento de sua pessoa, preparo para o exercício da cidadania e qualificação para o trabalho, assegurando-se lhes: I. igualdade de condições para o acesso e permanência na escola"; carecem de orientações vocacionais; precisam ter comportamentos de pró-atividade; devem ter responsabilidades; necessitam ser cidadãos democráticos, participativos ${ }^{3}$, empresários e investidores de si; deve fazer escolhas; "Art. 15. A criança e o adolescente têm direito à liberdade, ao respeito e à dignidade como pessoas humanas em processo de desenvolvimento e como sujeitos de direitos civis, humanos e sociais garantidos na Constituição”. Os jovens são multifuncionais, escuta-se nas ruas, nas mídias, nos corredores, nas instituições educacionais, nas casas e nas conversas informais. São agitados. São distraídos. São acelerados. São conectados. São desinteressados. São... São... São... São... São... São... (pul)são! ${ }^{4}$

Parte-se do pressuposto que o tempo presente apresenta sinais e vestígios indicados por autores como Deleuze (2008). A um tempo de marcas e modelos fixos de uma escola marcada pela disciplina e obediência, somam-se os modos voláteis, de fluxos, de modulações das subjetividades com características de democracia e participação.

\footnotetext{
${ }^{1}$ Por um lado, são constantemente rotulados como desinteressados pelos professores, pais e sociedade e, por outro lado, as provas nacionais como ENEM, os vestibulares causam insônia, calafrios, esquecimentos, nervosismo...

${ }^{2}$ Excertos do 'Estatuto da Criança e do Adolescente', Lei 8.069, de 13 de julho de 1990, com alterações pela Lei $\mathrm{n}^{\circ}$ 13.105, de 2015. Disponível em: 〈http://www.planalto.gov.br/ccivil_03/leis/L8069.htm>.

${ }^{3}$ Os temas participação e cidadania foram explorados em outros trabalhos de pesquisa das autoras.

4 A passagem em itálico é uma produção textual introdutória que apresenta um pouco das discurisividades contemporâneas sobre as juventudes, a composição escolar que produz subjetividades escolarizadas e os temas explorados neste artigo.
} 
Deleuze (2008) indica o final do século XX e início do século XXI como Sociedades de Controle em que os mecanismos disciplinares se ampliam e se reatualizam, na transposição em que "O homem da disciplina era um produtor descontínuo de energia, mas o homem do controle é antes ondulatório, funcionando em órbita, num feixe contínuo" (DELEUZE, 2008, p. 222-223). Apesar da indicação de uma passagem de uma sociedade a outra, as características da Sociedade Disciplinar ainda 'esburacam' (talvez ainda mais profundamente) a superfície contemporânea e deixam suas marcas e suas manchas; pois "quanto mais informação sobre você contenha o banco de dados, mais livremente você poderá se movimentar" (BAUMANN, 1999, p. 59). Os dados marcam, produzem estrias, mancham territórios, corroboram com os espaços institucionais (escolares) e identificam juventudes.

Dos espaços fechados do panóptico ao grande conjunto de dados armazenados pelo Big Data $^{5}$ que "[...] permite hacer pronósticos sobre el comportamento humano. De este modo, el futuro se convierte em predecible y controlable.” (HAN, 2014, p. 14).

Nos fluxos dos controles exacerbados, da grande quantidade de dados, das exigências sufocantes, das marcas e manchas na multidão dispersa, modulada e miscigenada, há movimentos das juventudes constituídos de grupos representativos, com influências externas e de interesses produzidos no interior de cada agrupamento específico (CARRANO; DAYRELL, 2014), algumas vezes homogêneos, com marcas e definições, instituídas nos coletivos ou institucionalmente; outros singulares, que não requerem uma identidade, são fluídas, tentam o descolamento dos controles e das exigências e deslizam sobre um (não) lugar com manifestações e expressões características das potências das juventudes.

As juventudes nestes movimentos podem ser entendidas como um "momento próprio de experimentações, de descobertas e testes das próprias potencialidades e de demandas de autonomia que se efetivam no exercício de escolhas.” (CARRANO; DAYRELL, 2014, p. 117). Porém, elas são comumente identificadas como uma fase em que apresenta familiaridade com os meios digitais, parece ter habilidades para navegar nos fluxos e realizar múltiplas tarefas. Alguns autores identificam os jovens como nativos digitais, nos quais nasceram, cresceram e desenvolveram-se em um tempo de grandes transformações tecnológicas digitais (PRENSKY, 2007).

Outra identificação das juventudes é pela idade, em que o Estatuto da criança e do adolescente (ECA) define esta etapa da vida entre 15 até 29 anos, considerando, basicamente,

\footnotetext{
5 "Big Data é o termo usado para descrever grandes volumes de dados; são cada vez mais relevantes à medida que a sociedade se depara com um aumento sem precedentes no número de informações geradas a cada dia”. Disponível em <https://www.oficinadanet.com.br/post/13252-o-que-e-big-data>.
} 
elementos objetivos em relação ao aspecto biológico e à delimitação das políticas públicas. $\mathrm{O}$ documento categoriza e simplifica a realidade complexa das juventudes, desconsiderando "elementos relacionados aos campos simbólico e cultural e aos condicionantes econômicos e sociais que estruturam as sociedades.” (CARRANO; DAYRELL, 2014, p. 110).

$\mathrm{Na}$ escolarização, por mais que haja uma representação de juventude, em uma subjetividade que pertence a uma categorização do que é escolar, há performatividades e singularidades que estão nesta mesma constituição. Portanto, "não há tanto uma juventude, e sim, jovens enquanto sujeitos que a experimentam e a sentem segundo determinado contexto sociocultural onde se inserem e, assim, elaboram determinados modos de ser jovem.” (CARRANO; DAYRELL, 2014, p. 112); há modos de estar/ser jovem, muitas vezes capturados e outras vezes inventivos, somados às condições sociais e econômicas, às diversidades culturais e às diferenças territoriais.

A escola, como um conjunto de regras e uma estrutura básica da escolarização, fez permanecer uma forma, que pouco se altera e constitui uma gramática da escolarização (DUSSEL, 2014). Na gramática da escolarização, algo permanece e materializa-se num espaço em que os jovens - agora os escolares - são separados do mundo adulto.

Aprender a aprender. Saber 'jogar o jogo'. Permanecer na escola. Estar e participar das atuações/ações escolares. A escola como uma 'forma', que escolariza cada um e alguns com uma configuração e uma estrutura compartilhadas pelos atores do espaço escolar, em que "A estrutura ou o sistema se impõe aos indivíduos; os agentes executam determinadas ações, porque a forma faz com que eles efetuem isto." (DUSSEL, 2014, p. 33). A forma escolar ligada a uma lógica disciplinar, funciona e atua sobre os escolares e sobre o que eles fazem, aumentando as forças sujeitadas e funcionando com o princípio do mínimo de prejuízo e o máximo de eficiência (FOUCAULT, 2005).

No contexto de globalização, as formas escolares mantêm-se, mas parecem ser ampliadas por novos dispositivos escolares, que têm sintonia com as discursividades globais.

Por um lado, as discursividades globais possibilitam a instauração de uma cultura da performatividade na qual "sustenta e é sustentada por tendências prescritivas que consideram importante formar para o atendimento às demandas econômicas" (LOPES, 2006, p. 47). Esta cultura segue uma lógica empreendedora e de mercado, que investem forças no desempenho, no capital e, na escola, faz com que os escolares sejam medidos/avaliados/rotulados diante de sua produtividade e seus resultados (BALL, 2010). Porém, também há espaço para a multiplicidade da 
vida cotidiana, em que impossibilita a desconsideração dos espaços, dos atores, dos conhecimentos, das normas e dos comportamentos (DUSSEL, 2014).

Quais os modos de subjetividades dos jovens diante das materialidades escolares e das performatividades? Que movimentos inventivos são possíveis? O texto segue com as perguntas.

A ordem do discurso contemporâneo é da personalização e da performatividade, que acompanha "La motivación, el proyeto, la competencia, la optimización y la iniciativa [como] inherentes a la técnica [...] del régimen neoliberal.” (HAN, 2014, p. 18-19). Na escola, nas redes sociais, nos grupos juvenis, as falas, os gestos e as ações soam imperativos: Personalize-se. Pense por si. Invista em si. Seja empresa de si. Publique, poste e compartilhe. Nas palavras de Han (2014), uma ditadura da transparência. Cria-se nas pessoas, e principalmente nos jovens, a necessidade de exposição, de dizerem o que 'pensam' e 'sentem', na qual 'La sociedad del control digital hace un uso intensivo de la libertad. [...] Así, la entrega de datos no sucede por coacción, sino por uma necesidad interna." (HAN, 2014, p. 12).

Capturas e resistências estão num mesmo fluxo, em que a captura é rápida, mas a resistência é instantânea, como o fogo e a faísca: o fogo permanece acesso, porém a faísca é imediata.

Diferente de apresentar identidades e representação, o que podem as juventudes? Elas podem ser deslocamentos, ser potência, criar desvios. Os movimentos podem ser fricção e, neste ato, criam atritos, produzem calor, energia e aí (podem) surgi(r)(em) a faísca e o pensamento. Porém, são (não estão) faíscas, e se apagam no momento seguinte.

\section{O CAMINHO}

Eis o campo de pesquisa que se acompanha em seus caminhos compostos de passos, falas, gestos, silêncios das juventudes que circulam num espaço escolar: uma escola estadual de ensino médio do interior de Santa Catarina, no Vale do Itajaí.

A observação foi realizada nos meses de novembro e dezembro de 2016, durante um período (matutino ou vespertino), em movimentos de aula, avaliação, recreio, eventos, formatura, início e final das aulas. As passagens dos tempos escolares são marcadas pelo sinal sonoro, pelo chamado dos professores e pelos próprios jovens que conhecem esses tempos.

Os movimentos foram registrados em um diário de bordo, com descrições e relatos das situações corriqueiras, habituais e inusitadas. 
A escolha da escola se deu pela abertura e aproximação das pesquisadoras com o município e por suas características, como: (i) a maior escola estadual de ensino médio do município, (ii) a localização central, (iii) trabalhar com o nível de ensino (Ensino Médio) e (iv) por receber estudantes de diferentes grupos econômicos e culturais, em que aglutina diferentes realidades e juventudes num mesmo espaço.

A pesquisa não analisa a escola e/ou os jovens, pensando em um julgamento ou um projeto de melhoria. Mas na ideia de amostra, por um lado generalizado de materialidades escolares e performatividades deste tempo e, por outro, dos modos inventivos que são possíveis (ou não) de os jovens experimentarem e exercerem potência em práticas e ações num espaço institucional, também rotulado e demarcado.

\section{DESCRIÇÃO-MOVIMENTOS DAS JUVENTUDES}

Socialmente, há definições etárias, comportamentais, atitudinais que marcam e apresentam os clichês das juventudes. Na escola, as materialidades, os protocolos comumente produzem subjetividades escolares. Os coletivos formados na escola ou em espaços sociais ou virtuais também constituem tipos de subjetividades. Porém, há forças inventivas difíceis de categorizar.

Com um diário de bordo, realizou-se um exercício de seguir, acompanhar e registrar os movimentos das juventudes no cotidiano escolar e seus modos de produção de subjetividades.

As descrições seguem nas tentativas de observar os detalhes do caminho, do que pode acontecer a partir de um espaço já institucionalizado: a escola.

O foco do olhar está nas juventudes: escolares? Performáticas? Inventivas? Elas se entrelaçam e embaralham-se. Capturar as potências inventivas seria impossível. Acompanhar, talvez. Separá-las e identificá-las? Não é o objetivo da pesquisa.

Distante da ingenuidade, os registros já são representações. Os movimentos protocolares são visíveis e, de certa forma, fáceis de registrar. As performatividades também. Porém, o que pulsa, o que é vida inventiva... ah, essa é transgressora. Escapa ao lápis, ao papel e ao olhar. Atreveu-se aqui a tentar também acompanhá-las em algumas partes sutis dos recortes do diário de bordo. O registro apresentado e intitulado descrição-movimentos é uma parte do que foi produzido durante o tempo da pesquisa na escola; inicia indicando os espaços (cenários), para em seguida, apresentar os dados em cenas do que foi visto, sentido e observado. 
Cenários. Escola: está localizada no centro de uma cidade do interior do estado de Santa Catarina; tem uma construção retangular, com sua fachada marcada por duas entradas: um grande portão de ferro, para entrada de carros e dos estudantes. Há dois pátios centrais, um utilizado mais no recreio como refeitório, com mesas para comer e outras mesas de jogos e outro utilizado para eventos escolares. Nas laterais, as salas de aula. Soa o sinal sonoro: o grande portão é fechado. Salas de aula: têm seus formatos e suas estruturas física semelhantes, com alguns poucos detalhes e medidas diferentes entre elas: a porta de entrada, um quadro branco, alguns cartazes na parte superior do quadro, um armário com uma televisão sob o armário, um ventilador fixo na parte superior da parede logo na entrada, a mesa do professor, fileiras de carteiras demarcadas pelos corredores, janelas grandes com cortinas; nas carteiras, quase sempre, os jovens.

Cenas $^{6}$. Sala de Aula: [...] há silêncio neste espaço; a professora $(\mathrm{P})$ coloca o filme 'Coração Valente' no projetor-computador posicionado em uma carteira e direcionado para sua projeção no quadro branco. Os estudantes (Es) assistem atentos; uns Es trocam rápidos comentários que parece ser sobre o filme; um E faz anotações em seu caderno de muitas matérias com largo espiral; dois Es mexem, disfarçadamente e rapidamente, nos celulares, com as mãos nos aparelhos embaixo das carteiras; outros dois Es conversam baixinho; há cenas de guerra e violência que geram nos Es comentários desconfortáveis e olhares de repulsa; as cenas engraçadas geram risadas e movimentos do corpo. Soa o sinal sonoro. A P sai da sala; os Es continuam assistindo o filme, sem agitação, mesmo com a ausência da P; pouco movimento; pouca conversa entre os Es; a próxima aula segue com o filme. Soa o sinal sonoro para o recreio. Um E interrompe o filme; alguns Es pedem para continuar; o E que desliga o aparelho parece não escutar, desliga o projetor e o leva para fora da sala, diz que entregará à P; outro E ascende a luz; Es reorganizam as carteiras; saem vagarosamente para o pátio da escola. Recreio. Não há silêncio, mas também nada muito exaltado entre os barulhos, conversas e movimentos dos Es; no pátio central há uma grande fila para merenda; dez Es usam celular, mas não é a principal ocupação; Es conversam em pequenos grupos, jogam pinguepongue, circulam em duplas/trios pelos corredores; há duas mesas de pingue-pongue, dois Es jogam em cada mesa e outros observam esperando sua vez; casais de Es namoram pela escola, circulam de mãos dadas e trocam beijos; Es percebem e comentam sobre minha presença; as salas de aulas estão destrancadas, abertas; alguns Es estão nas salas escrevendo em seus cadernos; no corredor das turmas de primeiros anos dois Es cantam e embalam-se no ritmo do RAP, tocado pelo celular; complementam a música com sons saídos das bocas. Soa o sinal sonoro. Os Es, aos poucos, bem

\footnotetext{
${ }^{6}$ As cenas escolares seguem em um texto contínuo, com recortes do diário de bordo construído. Para apresentar a ideia de continuidade esta parte é organizada em apenas um parágrafo.
} 
aos poucos, se dirigem às salas. Sala de aula: [...] o P entra na sala; um E escreve no quadro os nomes dos ausentes, sem o P solicitar; o P dá as orientações da aula: entrega mapas; Es escutam as orientações, respondem rápido o que é solicitado pelo $\mathrm{P}$ em relação ao mapa entregue; os Es logo iniciam a pintura do mapa, conforme indicação; Es pintam, pedem lápis de cores emprestados e relembram as orientações do $\mathrm{P}$ entre si; a conversa entre os Es, enquanto pintam os mapas, é sobre o próximo evento da escola, que é possível se caracterizar: E1: "Vem fantasiado dia 11?",; E2: “Claro, ganha um ponto!"; uma E chega atrasada, entra na sala, e pega um mapa na mesa do P; não pergunta ao $\mathrm{P}$ o que fazer, pergunta aos Es, que estão sentados próximos a ela; a maioria executa o exercício em duplas (aproximando as carteiras), sem perguntar ou pedir permissão ao P; pintam e comparam os mapas e cores; silenciosos, fazem a atividade, estão concentrados, trocando lápis e tecendo alguns breves comentários em torno da pintura do mapa: E1: "Aqui é o Brasil, aqui é a África.”; E2: “Olha a cor que o 'E' pintou com roxo!”; chamam o P para conferir se está certo. Soa o sinal sonoro. [...] Sala de Aula: Soa o sinal sonoro. Es entram na sala; três Es organizam seus skates no fundo da sala; encostam-os na parede; Es sentam-se em suas carteiras, o P entra; Es mostram imagens na tela do celular ao P; pelos comentários é sobre a fantasia do evento que ocorrerá, em breve, na escola; Es se cumprimentam: alguns com beijos no rosto, outros com palavras, outros com diferentes toques; em grupos, mostram fotos no celular; o P pede a um E para fazer a chamada; [...] o P anuncia a atividade: continuidade das apresentações dos trabalhos "Quem faz e como se faz o Brasil"; Es sabem a ordem das apresentações. Os grupos começam a se apresentar. Es sabem a ordem das apresentações; primeiro grupo de Es são responsáveis pelo assunto 'Salário Mínimo'; dois Es se dirigem para frente do quadro. Um deles começa: 'Boa tarde, linda turma' e continua sua fala com a leitura de uma reportagem que pesquisou, impressa em uma folha, que está em suas mãos; a reportagem indica o valor do salário mínimo, uma breve explicação e uma perspectiva de aumento do valor; outro $\mathrm{E}$ da equipe escreve o valor do salário mínimo no quadro, a pedido do P; um E: 'Que pobreza!'; uma E entra em sala atrasada, sem ser percebida e senta em uma cadeira vazia, que aparentemente, é seu lugar habitual; E explica sobre os impostos e seus valores; indica que, com os impostos, o valor do salário mínimo é menor que o anunciado; poucos Es olham os colegas apresentando; o outro E que apresenta relembra a aula de história e diz: 'Todos pagam impostos, de classe média e alta, o mesmo valor'. O P provoca, perguntando: 'Então, você acha justo? Não lutaram para isso?' E2: 'É injusto! E aqueles que só receberam herança?'. O P olha para mim satisfeito com o questionamento e a reflexão da E, mas não continua a discussão; o trabalho é finalizado e recebe aplausos de todos; um E liga o ventilador; outro E indica qual a

\footnotetext{
${ }^{7}$ Nesta parte, as palavras em itálico representam algumas falas registradas dos estudantes e/ou professores.
} 
próximo grupo que vai apresentar; este mostra as anotações do seu caderno ao $\mathrm{P}$ com a sequência dos grupos. [...] 'Vai, é vocês!', indica o E. Soa o sinal sonoro. [...] Sala de aula. P entra na sala, se dirige a sua mesa e coloca o material sob ela; um E aproxima-se da professora e tira dúvidas sobre o conteúdo; Es seguem para suas carteiras, sem a necessidade de alguma indicação verbal da P; Alguns Es abrem seus cadernos e/ou livros didáticos e escrevem algo; outros Es fazem leituras individuais/silenciosas; alguns Es conversam sobre uma festa que acontecerá no final de semana: baile funk; um E escreve no quadro: data e nome da matéria; cinco Es circulam pela sala sem chamar atenção e sem haver reclamação da P; [...] um E joga um jogo no celular, concentrado: movimenta o aparelho para acompanhar o jogo; uma E chega atrasada na sala; ela não é percebida pelo grupo e pela P; E senta em sua carteira e retira seu material; dois Es escutam música no MP3, compartilhando os fones, um fone para cada um e, silenciosamente, embalam-se pela música que escutam; um E pede material emprestado: uma caneta ao $\mathrm{E}$ do outro extremo da sala que lança o material solicitado; há silêncio, apesar de todo movimento; [...] cinco Es conversam com suas mochilas sobre as carteiras, o objeto abafa a conversa e se torna inaudível aos demais Es e P [...] Soa o sinal sonoro. Recreio: [...] sete Es conversam no pátio descoberto, localizado na parte lateral da escola; próximo a um barranco; os Es agrupados têm características semelhantes: bonés grandes, colocados de lado na cabeça; bermudas, calças e camisetas muito largas; fila para merenda; um E usa celular; digita algo, parecendo enviar alguma mensagem; três Es escutam um áudio no celular, sentadas em uma mesa no pátio central; riem e olham-se; mais risadas; nas mesas espalhadas no pátio coberto há mais grupos sentados e conversando; nos corredores casais caminham pela escola; pequenos grupos também circulam; alguns Es estão sentados no chão dos corredores; alguns sozinhos [...]; nos pilares há desenhos e caricaturas de personagens e flores. Soa o sinal. Aula de Educação física. Alguns Es jogam cartas em uma mesa do pátio; um E observa o jogo [...] um E entra no jogo de cartas; enquanto jogam, os fones de ouvidos estão conectados em um celular e são compartilhados, o que faz com que os Es fiquem mais silenciosos e próximos uns aos outros; os Es que escutam música movimentos o corpo, aparentemente no ritmo da música. [...] Dia de evento na escola. O movimento da escola é outro; os Es estão animados; circulam alegres e agitados pela escola; andam, correm e se encontram; nos encontros riem, se identificam e elogiam uns aos outros; os Es estão fantasiados; pelo menos a maioria; claro, 'vale 1,0 ponto'; Es 'encarnam' os personagens; tiram muitas fotos individuais, em duplas e em grupo. Há muitos registros fotográficos pelos Es em seus celulares. Soa o sinal sonoro. Es entram em agitação em suas salas; alguns já se encontravam em sala, dando o retoque final em sua maquiagem/fantasia; o P entra em sala; [...] caminho na escola, entro nas salas, registro por escrito e [...] tento tirar fotos dos grupos, de modo discreto, sem perceberem a lente da câmera, porém na maioria das vezes, quando me 
veem, logo se posicionam para o 'momento da foto', expõem sorrisos, biquinhos, línguas para fora da boca, poses...; o dia da escola é de circulação; [...] há música no ambiente; há descontração; há envolvimento dos Es no evento; há outra organização de escola: animação, conversas, risadas, brincadeiras e encontros; movimentos de espontaneidade entre os Es, que pulam, se agitam e incorporam as habilidades e os poderes de seus personagens; caminho pelos corredores e pátios da escola e observo: risadas, espanto, conversas, olhares, sorrisos; [...] predominam as fantasias de terror e os acessórios como armas de diferentes tipos; alguns Es vestem roupas curtas; outros encobrem seus corpos com a fantasia e o rosto com máscaras; os cabelos estão com diversos penteados não habituais: escovados, lisos, coloridos, para o lado, para cima, bagunçado, variando conforme o personagem; outros (alguns poucos) não tem fantasias [...].

\section{PELOS MOVIMENTOS DAS JUVENTUDES}

Os protocolos, os movimentos da escola e seus rituais fazem algo (não-novo) acontecer, na maioria das vezes, sem a condução verbal dos professores; os estudantes parecem conhecer o jogo e o que deve ser feito: ao sinal sonoro, no momento de entrar, sair ou trocar de aula; diante da folha na carteira entregue pelo professor, a hora da alimentação, o momento de realizar a(s) atividade(s) e outros ritos escolares.

Os estudantes cumprem com os protocolos escolares, seguem os comandos (ditos e não ditos) e alguns (poucos) não os fazem. Em muitos momentos, o movimento parece marcado pelos estudantes, em que o professor não indica mais o comando. Todo o processo escolar está explícito: prova, frequência, exercício, permanência em sala de aula; não parece haver motivo para ocultar. Estudantes conhecem as regras do jogo escolar e os jogam: começo, meio e fim.

Há diálogo entre os estudantes, durante o recreio e as aulas. Há alguns estudantes (poucos) que parecem não se importar com o que acontece na aula, parecem que não estão presentes no ambiente: não realizam atividades, não vestem fantasias, não participam, não estão atentos, não atrapalham as aulas, não incomodam os professores. Outros estudantes (a maioria) estão focados: resolvem a(s) atividade(s) e prova(s), 'prestam a atenção no conteúdo', participam dos eventos. No momento da execução de uma atividade, o exercitar parece ser a ação mais importante naquele momento. As 'caras' demonstram preocupação, atenção, dedicação e esforço: realizam exercícios, trocam olhares de preocupação, ajudam-se uns aos outros, preparam-se, confeccionam seus trajes e preenchem as fichas dos personagens para o evento. Querem resolver os exercícios. Entregar a prova. Querem parecer o personagem, os incorporam! 
Há muitos movimentos escolares que não precisam ser comunicados ou solicitados pela fala; acontece (mesmo que nada novo aconteça); em outros momentos percebe-se que esperam (e até comemoram, quando ninguém os olha) a ausência do professor; mesmo que isso não significa a saída antecipada da escola.

O conteúdo, os cadernos e os livros didáticos são o foco; são objeto de atenção. Os gestos, os olhares, os movimentos marcam e materializam-se: naqueles momentos são escolares.

Há materialidades escolares. A disposição da sala, a organização da aula, a condução dos professores, os gestos, os movimentos e as falas dos jovens-estudantes, o uniforme, os materiais: os cadernos, os penais com canetas de diferentes cores, borracha, lápis, restos de lápis apontado; as mochilas com diferentes cores e estilos; o livro didático que transita do armário do professor até as carteiras dos estudantes. O conteúdo parece ser o foco das aulas e das conversas entre os estudantes durante as aulas; as vezes, até mesmo durante o recreio ou no intervalo das aulas.

Há uma tentativa de padronização nos uniformes, nas posturas, nas carteiras e nas cadeiras das salas de aula e em toda e estrutura física e simbólica escolar. Mas nos corpos não há padronização. Nos coletivos e na formação de grupos há identificações pelas roupas, músicas, estilos, cumprimentos, modos de falar, agir, andar. O RAP embala um grupo. A roupa justa e com lycra apresenta o estilo de outro. Os bonés largos são de um coletivo.

No dia de evento da escola, os numerosos registros fotográficos realizados pelos jovens conseguem, em alguns momentos, agrupar os que se sentem semelhantes ou diferenciá-los ainda mais. Em alguns momentos, mesmo no local escolar, criam movimentos distintos das materialidades: um lugar dentro de um lugar como fendas, em que os estudantes criam espaçotempo $\left[\mathrm{o} \mathrm{pico}^{8}\right]$ dentro da própria sala, no recreio, nos corredores, em situações no contexto escolar.

Os celulares aparecem nos registros. São como acessórios nas mãos; usam, porém ele está mais como objeto de identificação e semelhança entre os coletivos, como uma pulseira, um anel, um brinco, um boné, que apenas precisa ser visto, que tem função quiçá performática. O uso do celular é, na maioria das situações, para ouvir música e, geralmente, seus fones são compartilhados com algum colega. Os fones aparecem, muitas vezes também, também como acessório: estão pendurados nas camisetas dos estudantes.

\footnotetext{
${ }^{8}$ No dicionário, como ponto mais alto de uma montanha, cume; na linguagem dos jovens um local muito bom, especial, diferente, um lugar de encontro.
} 
Os jovens criam movimentos, toques, frases, expressões, que são deles e tem sentido no momento presente. Os registros captam pouco do vivenciado e possibilitado: os encontros, as risadas, os sorrisos, os gestos... as pulsões.

Os movimentos observados, as conversas, os olhares e a colaboração entre os jovens (como, por exemplo, um empréstimo de material), que parecem (e também é) materialidades escolares, pode ser cuidado e atenção.

Acontecimentos e situações dos mais singulares e inesperados em que há dificuldade do diário de bordo captá-los. Eis o desafio, seguir pelas imprevisibilidades e conseguir (talvez) percebê-las em seu momento de ação/silêncio.

Escola, materialidades e formas escolares. Subjetividades. Juventudes. Inventividades. Estar no momento presente, nos acontecimentos em que nada/algo pode acontecer entre os envolvidos da pesquisa, os jovens, em que afetam e são afetados pelos movimentos escolares.

Os movimentos dos jovens, mesmo nos espaços escolares, podem criar (novos) acontecimentos e inventividades que se 'desmancham' ao aproximarem suavemente ou violentamente do instituído. Surge assim, a possibilidade de criar um espaço-entre, logo, um espaço intermediário de passagem, conectado a partir do ponto de vista dos indivíduos jovens.

\section{O CAMINHO SEGUE, ACOMPANHA AS JUVENTUDES}

Uma conversa com textos e ideias e dados produzidos na escola estadual de ensino médio. No momento, é esta a caminhada; reconhecem-se os clichês, mas se percebe uma abertura para acompanhar e pensar as potências das juventudes. Músicas nos fones, pedaços de textos, escritos, cores, sons, gargalhadas, sussurros, silêncios. A possibilidade de provocar inventividades num ambiente escolar: quais as possibilidades? A pergunta segue com a pesquisa.

Seguir e respirar outros 'ares' num mesmo ar-ambiente (escolar) que, comumente, mais sufoca e imobiliza do que movimenta. Mover-se, agir, sentir, experimentar: uma faísca, um segundo, um(ns) momento(s) possível(is). Demolição das formas protocolares de ação e a possibilidade (talvez) das inventividades.

Os registros dizem muito de materialidades escolares, práticas protocolares e performáticas, mas também, de algumas inventividades. Movimentos que se mesclam em emaranhados, impossíveis sua separação e/ou identificação isolada, mas que pulsam e estão em movimento. 
Distante das juventudes enquanto categoria ou produção social, pensa-as enquanto suas próprias características de potência e movimentos constantes e enquanto modos de subjetividades possibilitados nas micropolíticas.

Acompanhar o processo, seguir o phylum, sem alcançar e esperar pelo fim, mas acompanhar a caminhada. $\mathrm{O}$ agir do corpo enquanto arma às imobilidades. Armas nômades... produzidas... que seguem a matéria. Como o artesão, que segue a materialidade que ele modula (GODOY, 2008).

O 'ar' comumente sufoca, mas têm outros ares, brechas, intervalos, juventudes. Há forças em todos os sentidos, deslizamentos em territórios conhecidos e desconhecidos e há potência micropolítica; com possibilidade de

[...] liberar a ação educativa curricular de toda forma de paranoia unitária e totalizante, fazendo crescer a ação, o pensamento e os desejos [...] a partir de uma multiplicidade de encontros, produzindo agenciamentos coletivos de enunciação em torno das 'matérias' escolares. (CARVALHO; SILVA; DEBONI, 2017, p. 485).

Em meio a tantas ocupações e consumos, há agenciamentos que possibilitam modos inventivos de juventudes, que transbordam o modo prescritivo e disciplinar de ser jovem, justamente pelas características e potencialidades que elas possuem. 


\section{REFERÊNCIAS}

BALL, S. Profissionalismo, Gerencialismo. Performatividades e fabricações na economia educacional: rumo a uma sociedade performativa. Educação e realidade, v. 35, n. 2, 2010, p. 37-55. Disponível em: <http://seer.ufrgs.br/ index.php/educacaoerealidade/article/view/15865/9445>. Acesso em 30 set 2017.

BRASIL. Estatuto da criança e do adolescente. Lei 8.069, de 13 de julho de 1990. Disponível em: <http://www.planalto.gov.br/ccivil_03/leis/L8069.htm>. Acesso em: 30 set 2017.

BAUMAN, Zigmunt. Globalização: as consequências humanas. Rio de Janeiro: Zahar, 1999.

CARRANO, Paulo; DAYRELL, Juarez. Juventude e Ensino Médio: quem é este aluno que chega à escola. In: DAYRELL, Juarez; CARRANO, Paulo; MAIA, Carla Linhares (orgs.). Juventude e Ensino médio: sujeitos e currículos em diálogo. Belo Horizonte: UFMG, 2014.

CARVALHO, Janete Magalhães; SILVA, Sandra Kretli; DEBONI, Tania Mara Z G. F. A Base Nacional Comum e a produção biopolítica da educação como formação de 'capital humano'. Revista e-Curriculum, São Paulo, v. 15, n. 2, p. 481 - 503 abr./jun.2017. Disponível em: <https://revistas.pucsp.br/index.php/curriculum/article/view/27679>. Acesso em: $01 \mathrm{dez} 2017$.

DELEUZE, Gilles. Conservações. São Paulo: Editora 34, 2008.

; GUATTARI, Félix. Mil Platôs: Capitalismo e Esquizofrenia. 3 reimp. São Paulo: Ed. 34, 2007. Vol. 5.

DUSSEL, Inés. A montagem da escolarização: discutindo conceitos e modelos para entender a produção histórica da escola moderna. Revista Linhas, Florianópolis, v. 15, n. 28, p. 250-278, jan./jun. 2014.

FOUCAULT, Michel. Em defesa da Sociedade. São Paulo: Martins Fonte, 2005.

GODOY, Ana. A menor das ecologias. São Paulo: Edusp, 2008.

HAN, Bying-Chul. Psicopolítica: neoliberalismo y nuevas técnicas de poder. Barcelona: Helder, 2014.

LOPES, Alice Casimiro. Discursos nas políticas de currículo. Currículo sem fronteiras, v. 6, n. 2, p. 33-52, Jul./Dez. 2006. Disponível em: < http://escoladegestores.mec.gov.br/site/8-biblioteca/pdf/discurso_nas_politicas_de_curriculo_ Lopes. pdf>. Acesso em 30 set 2017.

PRENSKY, Marc. Digital game-based learning. St. Paul (Minnesota): Paragon House, 2007.

PREVE, Ana Maria. Mapas, prisão e fugas: cartografias intensivas em educação. Tese (Doutorado em Educação) Universidade Estadual de Campinas, 2010. 


\section{RESUMO}

O artigo é um recorte de uma pesquisa de doutorado que objetiva cartografar os movimentos das juventudes contemporâneas num espaço de escolarização. Os movimentos cartografados percorreram por materialidades escolares, performatividades e inventividades, não de modo separados, mas embaralhados e na constituição de macro e micropolíticas. O campo de pesquisa é uma escola estadual de ensino médio. Os movimentos foram registrados com um diário de bordo, com descrições e relatos. Com a produção dos dados pelo caminho da cartografia, percebeu-se que os movimentos dos jovens seguem pela ordem das normas e dos modelos e pelas brechas micropolíticas como potências criadoras em que algo pode acontecer. Permeados pelas relações de poder, os dados indicam que os jovens afetam e são afetados pelos emaranhados de materialidades escolares, performatividades e inventividades.

Palavras-chave: juventudes, escolarização, micropolíticas.

\section{YOUTH IN MOVEMENTS: SCHOOL MATERIALS, PERFORMANCES AND INVENTIVENESS ABSTRACT}

The article is a cut of a doctoral research that aims to map the movements of contemporary youth in a schooling space. The mapped movements traveled through school materialities, performativity and inventiveness, not in a separate but shuffled way, and in the constitution of macro and micropolitics. The field of research is a state high school. The movements were recorded with a logbook, with descriptions and reports. With the production of the data along the path of cartography, it has been observed that the movements of young people follow the order of norms and models and the micropolitical gaps as creative powers in which something can happen. Permeated by power relations, the data indicate that young people affect and are affected by the tangles of school materialities, performativity and inventiveness.

Keywords: youths, schooling, micropolitics.

\section{JUVENTUDES EN MOVIMIENTOS: MATERIALES ESCOLARES, PERFORMATIVIDADES Y INVENTIVIDADES RESUMEN}

El artículo es un recorte de una investigación de doctorado que objetiva cartografiar los movimientos de las juventudes contemporáneas en un espacio de escolarización. Los movimientos cartografiados recorrieron por materialidades escolares, performatividades e inventividades, no de modo separados, sino barajadas y en la constitución de macro y micropolíticas. El campo de investigación es una escuela estatal de educación media superior. Los movimientos se registraron con un diario de a bordo, con descripciones y relatos. Con la producción de los datos por el camino de la cartografía, se percibió que los movimientos de los jóvenes siguen por el orden de las normas y de los modelos y por las brechas micropolíticas como potencias creadoras en que algo puede suceder. Permitados por las relaciones de poder, los datos indican que los jóvenes afectan y son afectados por los enmarañados de materialidades escolares, performatividades e inventividades.

Palabras-clave: juventudes, escolarización, micropolíticas. 